\title{
Determining $\mathrm{K}^{+}$channel activation curves from $\mathrm{K}^{+}$channel currents often requires the Goldman-Hodgkin-Katz equation
}

\author{
John R. Clay* \\ Ion Channel Biophysics Group, National Institute of Neurological Disorders and Stroke, National Institutes of Health, Bethesda, MD, USA
}

\section{Edited by:}

Daniel Johnston, University of Texas, USA

\section{Reviewed by:}

Alon Korngreen, Bar-llan University, Israel

Xixi Chen, University of Texas, USA

${ }^{*}$ Correspondence:

John R. Clay, TN-41, Twinbrook Bldg., 5625 Fishers Lane, Rockville, MD 20892, USA.

e-mail:.jrclay@ninds.nih.gov
Potassium ion current in nerve membrane, $I_{k^{\prime}}$, has traditionally been described by $I_{K}=g_{K}\left(V-E_{k}\right)$, where $g_{k}$ is the $\mathrm{K}$ ion conductance, $V$ is membrane potential and $E_{K}$ is the $\mathrm{K}^{+}$Nernst potential. This description has been unchallenged by most investigators in neuroscience since its introduction almost 60 years ago. The problem with the $I_{K} \sim\left(V-E_{K}\right)$ proportionality is that it is inconsistent with the unequal distribution of $\mathrm{K}$ ions in the intra- and extracellular bathing media. Under physiological conditions the intracellular $\mathrm{K}^{+}$concentration is significantly higher than the extracellular concentration. Consequently, the slope conductance at potentials positive to $E_{k}$ cannot be the same as that for potentials negative to $E_{k^{\prime}}$ as the linear proportionality between $I_{k}$ and $\left(V-E_{k}\right)$ requires. Instead $I_{k}$ has a non-linear dependence on $\left(V-E_{k}\right)$ which is well described by the Goldman-Hodgkin-Katz equation. The implications of this result for $\mathrm{K}^{+}$channel gating and membrane excitability are reviewed in this report.

Keywords: ion permeation, channel gating, membrane excitability

\section{INTRODUCTION}

Potassium ion current - the primary repolarization mechanism in nerve membrane-has often been described by $I_{\mathrm{K}}=g_{\mathrm{K}}(V, t)\left(V-E_{\mathrm{K}}\right)$ where $g_{\mathrm{K}}$ is the $\mathrm{K}^{+}$voltage- and time-dependent conductance, $V$ is membrane potential, and $E_{\mathrm{K}}$ is the $\mathrm{K}^{+}$Nernst potential. This description was given by Hodgkin and Huxley (1952) in their classic work on squid giant axons. A central assumption of their analysis is that $I_{\mathrm{K}}$ is linearly proportional to the driving force $\left(V-E_{\mathrm{K}}\right)$. Several studies since Hodgkin and Huxley (1952) including work on squid giant axons (Frankenhauser, 1962; Binstock and Goldman, 1971; Siegelbaum et al., 1982; Clay, 1991; Taglialatela and Stefani, 1993) have shown that $I_{\mathrm{K}}$ has a non-linear dependence on $\left(V-E_{\mathrm{K}}\right)$ for physiological conditions which is well described by the Goldman-Hodgkin-Katz equation (Goldman, 1943; Hodgkin and Katz, 1949), referred to here for brevity as GHK. The purpose of this review is to describe the GHK result and its implications for both the voltage dependence of $g_{\mathrm{K}}$ and models of membrane excitability.

\section{GHK ANALYSIS}

An example of a $\mathrm{K}^{+}$current-voltage relation from squid giant axons is given in Figure 1 (taken from Clay et al., 2008). This result has a curvature in the outward direction with increasing membrane depolarization from the rest level. The curve labeled GHK $\left[\left(V-E_{\mathrm{K}}\right)\right]$ represents $I_{\mathrm{K}}=P_{\mathrm{K}} F(F V / R T)\left(\mathrm{K}_{\mathrm{i}}^{+} \exp (F V / R T)-\mathrm{K}_{\mathrm{o}}^{+}\right) /(\exp (F V / R T)-1)$ which is equivalent to

$$
I_{\mathrm{K}}=P_{\mathrm{K}} F\left(\frac{F V}{R T}\right) \mathrm{K}_{\mathrm{o}}^{+}\left(\exp \left(\frac{F\left(V-E_{\mathrm{K}}\right)}{R T}\right)-1\right)\left(\exp \left(\frac{F V}{R T}\right)-1\right),
$$

where $P_{\mathrm{K}}$ is the membrane's permeability to $\mathrm{K}^{+}, F$ is the Faraday constant, $R$ is the gas constant, $T$ is the absolute temperature, and $E_{\mathrm{K}}$, the Nernst potential, is given by $R T / F \log \left[\mathrm{K}_{\mathrm{o}}^{+} / \mathrm{K}_{\mathrm{i}}^{+}\right]$where $\mathrm{K}_{\mathrm{o}}^{+}$and $\mathrm{K}_{\mathrm{i}}^{+}$are the extra- and intracellular $\mathrm{K}^{+}$concentrations, respectively. [Note that $\mathrm{K}_{\mathrm{o}}^{+} \exp \left(-F E_{\mathrm{K}} / R T\right)=\mathrm{K}_{\mathrm{i}}^{+}$]. At room temperature $R T / F=25 \mathrm{mV}$. Throughout the remainder of this review $R T / F$ is replaced by 25 . The value of $P_{\mathrm{K}}$ derived from the results in Figure 1 is $1.25 \times 10^{-2} \mathrm{~cm} \mathrm{~s}^{-1}$ as compared to $1.2 \times 10^{-3} \mathrm{~cm} \mathrm{~s}^{-1}$ for frog node of Ranvier, the preparation in which the GHK result was first demonstrated (Frankenhauser, 1962). This comparison suggests that $\mathrm{K}^{+}$is 10 times more permeable in squid giant axons relative to frog nerve (see Summary). One question which arises from these results is what is the GHK equivalent at the single channel level? $\mathrm{K}$ ions are believed to pass through $\mathrm{K}^{+}$selective channels in a single file manner along a row of three $\mathrm{K}^{+}$binding sites (Hodgkin and Keynes, 1955; Zhou et al., 2001). This result is schematically illustrated in the top left inset of Figure 2. Two sites are shown to be occupied by a $\mathrm{K}$ ion which is consistent with the view of several groups (Hodgkin and Keynes, 1955; Kohler and Heckmann, 1979; Shumaker and MacKinnon, 1990; Clay, 1991) that a $\mathrm{K}^{+}$channel contains at most a single "vacancy" and that movement of $\mathrm{K}^{+}$through the channel can be viewed as movement of the "vacancy" through the channel. The prediction of the model is (Clay, 1991)

$$
I_{\mathrm{K}}=a q N_{\mathrm{K}} \mathrm{K}_{\mathrm{o}}^{+} \frac{\left(\exp \left(\frac{-\left(2 d_{1}+d_{2}\right) V}{25}\right)\right)\left(\exp \left(\frac{\left(V-E_{\mathrm{K}}\right)}{25}\right)-1\right)}{\cosh \left(\frac{d_{1} V}{25}\right)\left(\exp \left(\frac{3 d_{2} V}{25}\right)+2 \cosh \left(\frac{d_{2} V}{25}\right)\right)}
$$

where $a$ is the frequency of collisions of $\mathrm{K}$ ions with the channel, $N_{\mathrm{K}}$ is the $\mathrm{K}^{+}$channel density (typically $100 \mu^{-2}$ for nerve membrane, Conti et al., 1975), $q$ is the unit electronic charge, $d_{1}=0.07$, and $d_{2}=0.18$. The parameter $a$ is given by $9.1 \times 10^{6} \mathrm{~s}^{-1} \mathrm{M}^{-1}$ which is consistent with the view that the transit time of an ion through a channel is $\sim 10^{-7} \mathrm{~s}$ (Hille, 2001). Equation 1 is described by the dashed line labeled "a" in Figure 2. This result is virtually indistinguishable 


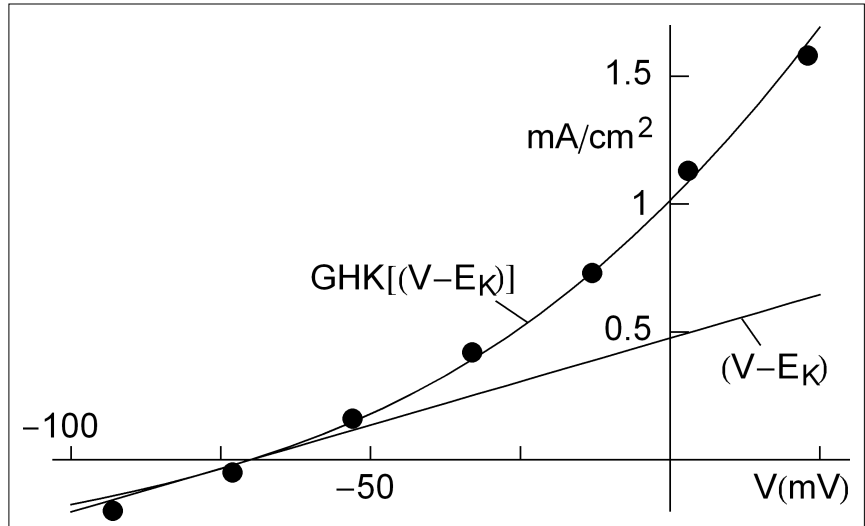

FIGURE 1 | Squid axon $I_{\mathrm{K}}$ has a non-linear dependence on $\left(V-E_{\mathrm{K}}\right)$ which is well described by GHK - Eq. 1 in the text - curve labeled GHK[(V - $\left.\left.E_{K}\right)\right]$. Specifically, $I_{\mathrm{K}}=P_{\mathrm{K}} F \mathrm{~K}_{\mathrm{o}}^{+}(\mathrm{FV} / \mathrm{RT})\left(\exp \left(F\left(V-E_{\mathrm{K}}\right) / R T\right)-1\right) /(\exp (F V / R T)-1)$, where $P_{\mathrm{K}}=1.25 \times 10^{-2} \mathrm{~cm} \mathrm{~s}^{-1}, \mathrm{~F}$ is $9.65 \times 10^{4}$ coulombs, $\mathrm{K}_{\circ}^{+}=10 \mathrm{mM}$, and $R T / F=25 \mathrm{mV}$.

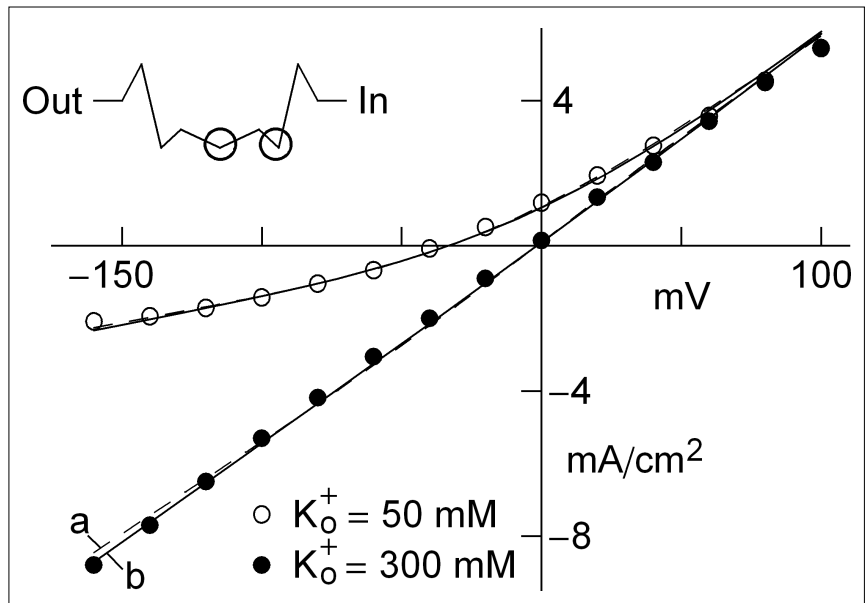

FIGURE $2 \mid \mathrm{K}_{\circ}^{+}$dependence of $\boldsymbol{I}_{\mathbf{K}}$ in squid axons. The solid curves (labeled "b", for example, in lower left hand corner) are a description of these results by GHK. The dashed lines (labeled "a") represent Eq. 2 in the text. The diagram in the upper left is a schematic illustration of single "vacancy" ion translocation described in the text.

from the GHK equation for $-150<V<100 \mathrm{mV}$ and so the simpler GHK result is used for the rest of this review in particular the GHK voltage dependence which is given by

$\operatorname{GHK}\left[\left(V-E_{\mathrm{K}}\right)\right]=\left(\frac{V}{25}\right) \frac{\left(\exp \left(\frac{\left(V-E_{\mathrm{K}}\right)}{25}\right)-1\right)}{\left(\exp \left(\frac{V}{25}\right)-1\right)}$.

\section{VOLTAGE DEPENDENCE OF CHANNEL GATING - SIGNIFICANCE OF GHK}

Two primary types of voltage-gated $\mathrm{K}^{+}$channels in nerve membrane (Jan and Jan, 1997) are the delayed rectifier (Kv2; Kv3) and the rapidly inactivating $\mathrm{K}^{+}$channel $(\mathrm{Kv} 4 ; \mathrm{Kv} 1.4)$ often referred to as $I_{\mathrm{A}}$. An example of recordings of the latter are shown in the right hand panel of Figure 3. These results were obtained from Cajal-Retzius cells in the early postnatal rat brain (Mienville et al., 1999). Similar results have been observed from many preparations. The $I_{\mathrm{A}}$ component is rapidly activated with a depolarizing voltage step followed by a somewhat slower time course of inactivation. Activation is so much more rapid than inactivation that the peak current $\left(I_{\mathrm{A}, \mathrm{p}}\right.$ in Figure 3 ) can be used as an approximation of the steady-state current which would occur at any given voltage if inactivation were absent. Those results have traditionally been normalized by the driving force $\left(V-E_{\mathrm{K}}\right)$ as indicated by the open circles in Figure 3. One of the primary arguments of this review is that this procedure should be replaced by one in which normalization by $\operatorname{GHK}\left[\left(V-E_{\mathrm{K}}\right)\right]$ is used instead. The analysis is illustrated in Figure 3. The open circles were multiplied by $\left(V-E_{\mathrm{K}}\right)$ to remove the linear normalization. The results thus obtained were divided by GHK $\left[\left(V-E_{\mathrm{K}}\right)\right]-$ Eq. 3 above. This set of points (filled circles) clearly saturate with depolarization. In particular the results for $V=20,30$ and $+40 \mathrm{mV}$ are virtually identical. Those results were averaged and that average value was used to normalize all the points. $I_{\mathrm{K}}$ activation curves such as those in Figure 3 have traditionally been modeled by the Boltzmann equation, $\left(1+\exp \left(-\left(V-V_{1 / 2}\right) / k\right)\right)^{-1}$, as illustrated by the dashed curve (Figure 3 ) where $V_{1 / 2}$ is the voltage of half-maximal activation and $k$ represents its steepness. A better fit to either set of results - the open or the closed circles - can be obtained using a model consisting of several Boltzmann equations. An alternative approach is provided by Hodgkin and Huxley (1952). They modeled $\mathrm{K}^{+}$channel gating (the delayed rectifier) by $n(V, t)=-\left(\alpha_{n}+\beta_{n}\right) n(V, t)+\alpha_{n}$ where $0 \leq n \leq 1$, and $\alpha_{n}$ and $\beta_{n}$ are voltage-dependent. They raised the $n$ parameter to the 4 th power to account for the sigmoidal time-dependent rise of $I_{\mathrm{K}}$ following a voltage step. An $n^{3}$ model has been used for $I_{\mathrm{A}}$ activation kinetics (Campbell et al., 1993). The activation curve for $I_{\mathrm{A}}$ in this model is given by $n_{\infty}^{3}(V)=\left(\alpha_{n} /\left(\alpha_{n}+\beta_{n}\right)\right)^{3}$ with $\alpha_{n}$ and $\beta_{n}$ for the curve (solid line) in given in the legend of Figure 3. A similar analysis of $I_{\mathrm{A}}$ over a broader voltage range is illustrated in Figure 4 (Mienville and Barker, 1997). The activation curve obtained with GHK normalization clearly saturates with depolarization. In contrast normalization by $\left(V-E_{\mathrm{K}}\right)$ becomes problematic as increasingly large depolarizations are used (open circles, Figure 4). This argument has some circularity, although voltage-gated channels have been clearly shown to be steeply voltage-dependent (Sigworth, 2003), a dependence which can be demonstrated by other procedures such as deactivation, or "tail" current analysis (Zagotta et al., 1994). The steep voltage dependence is revealed from a family of $\mathrm{K}^{+}$currents by GHK normalization.

\section{GHK NORMALIZATION - SIGNIFICANCE FOR MODELS OF EXCITABILITY}

Some modeling studies have been carried out concerning the role of $I_{\mathrm{A}}$ in neuronal excitability (Connor and Stevens, 1971; Rush and Rinzel, 1995), but this issue has not yet been fully resolved (Khaliq and Bean, 2008). Consequently, the effect of GHK normalization of $I_{\mathrm{A}}$ on excitability cannot yet be determined. In contrast the delayed rectifier $I_{\mathrm{K}}$ is clearly significant for repolarization of the action potential as demonstrated by Hodgkin and Huxley (1952). That analysis uses a linear dependence for $I_{\mathrm{K}}$ and $\left(V-E_{\mathrm{K}}\right)$. A similar result 


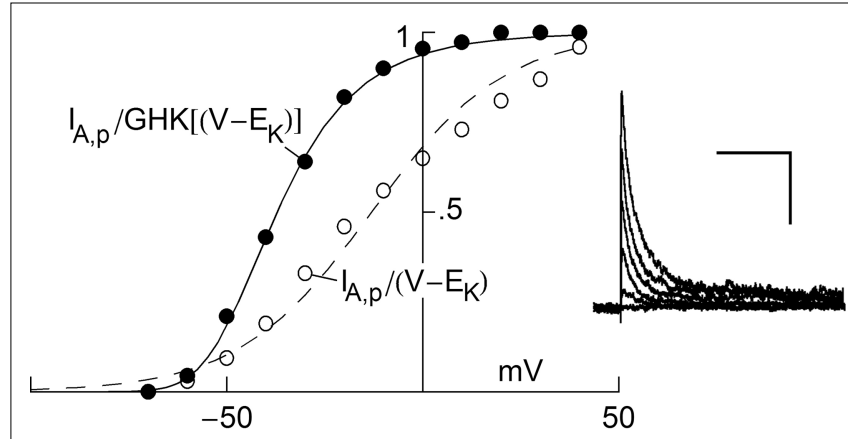

FIGURE 3 | GHK analysis of $\boldsymbol{I}_{\mathbf{A}}$. The records in the right were taken from (Mienville et al., 1999). The scales correspond to $100 \mathrm{~ms}$ and 400 pA. The open circles in the graph correspond to peak $I$ at the respective potential on the $x$-axis divided by $\left(V-E_{K}\right)$ where $E_{K}=-96 \mathrm{mV}$. The filled circles represent peak I divided by GHKI(V-E $)]-$ Eq. 3 in the text. The dashed line corresponds to $1 /\left(1+\exp \left(\left(V-V_{1 / 2}\right) / k\right)\right)$, where $V_{1 / 2}=-17$ and $k=-18 \mathrm{mV}$. The solid line corresponds to $\left(\alpha_{r} /\left(\alpha_{n}+\beta_{n}\right)\right)^{3}$, where $\alpha_{n}=-0.01(V+51) /(\exp (-0.1(V+51))-1)$ and $\beta_{n}=0.125 \exp (-(V+61) / 25)$.

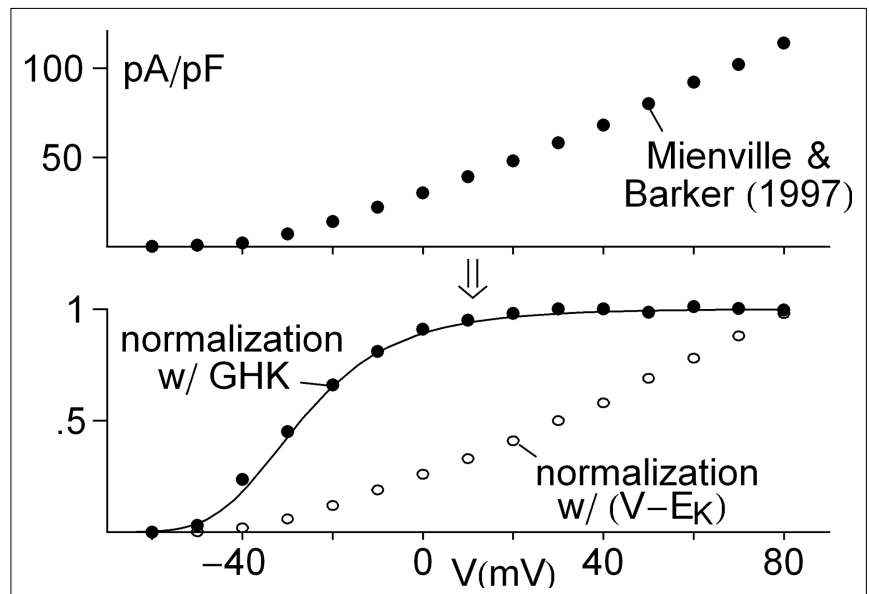

FIGURE 4 | Further evidence for saturation of $\mathrm{K}^{+}$channel activation with membrane depolarization. The top panel illustrates peak $I_{A}$ results from Mienville and Barker (1997). Normalization of those results by GHKI(V-E $\left.\left.E_{k}\right)\right]$ and $\left(V-E_{k}\right)$ are given in the bottom panel. The theoretical curve is a description of the former by $\left(\alpha_{n} /\left(\alpha_{n}+\beta_{n}\right)\right)$ with $\alpha_{n}=-0.01(V+41) /$ $(\exp (-0.1(v+41))-1)$ and $\beta_{n}=0.125 \exp (-(V+41) / 25)$.

for repolarization is obtained with the GHK relationship for $I_{\mathrm{K}}$ (simulations not shown). The $I_{\mathrm{K}}$ component is more subtly involved in repetitive firing in the Hodgkin and Huxley (1952) model. For this result GHK normalization is required. The $I_{\mathrm{K}}$ activation curve obtained by Hodgkin and Huxley (1952) using normalization with $\left(V-E_{\mathrm{K}}\right)$ is illustrated in Figure 5 (curve labeled " $\mathrm{HH} n_{\infty}^{4}(V)$ "). This curve has a shallow voltage dependence similar to the $I_{\mathrm{A}}$ results (open circles in Figure 3 ) which Hodgkin and Huxley described by $n_{\infty}^{4}(V)=\left(\alpha_{n}(V) /\left(\alpha_{n}(V)+\beta_{n}(V)\right)^{4}\right.$ with $\alpha_{n}$ and $\beta_{n}$ given in the legend of Figure 5. Normalization of $I_{\mathrm{K}}$ in squid giant axons by $\mathrm{GHK}\left[\left(V-E_{\mathrm{K}}\right)\right]$ yields a steeper voltage dependent relation (Figure 5, filled circles). The curve describing those points is the same as in the Hodgkin and Huxley (1952) model with one change in their $\beta_{n}$ parameter (Figure 5 legend). This modification is sufficient to

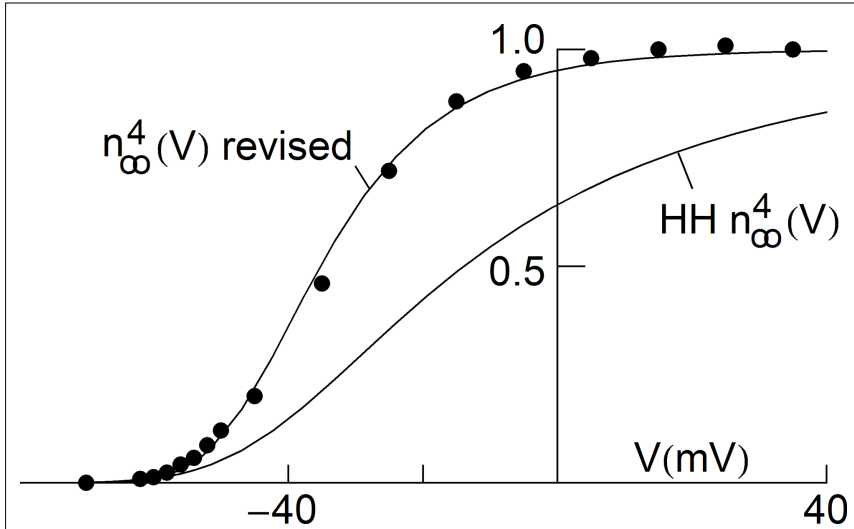

FIGURE 5 | Normalization of squid $\boldsymbol{I}_{\mathbf{K}}$ activation by GHK (filled circles). The curve describing these results $\left(n_{\infty}^{4}(V)\right.$ revised) corresponds to $\left(\alpha /\left(\alpha_{n}+\beta_{n}\right)\right)^{4}$ where $\alpha_{n}=0.01(V+50) /(\exp (-0.1(V+50))-1)$ and $\beta_{n}=0.125$ $\exp (-(V+60) / 20)$. The curve labeled $\mathrm{HH} n_{\infty}^{4}$ is given by the same equation with $\beta_{n}=0.125 \exp (-(V+60) / 80)$

describe both the $I_{\mathrm{K}}$ activation curve and the response of the axon to long duration depolarizing current pulses (Clay et al., 2008). The revised model fires only once (middle panel, Figure 6) which is consistent with experimental results (bottom panel, Figure 6). In contrast the Hodgkin and Huxley (1952) model fires an unending train of action potentials in response to a sustained depolarizing current pulse (Figure 6, top panel). The mechanism underlying this result in the revised model is described in Clay et al. (2008).

A second example of the significance of GHK normalization for models of excitability concerns neurons from the suprachiasmatic nucleus (SCN) in the mammalian brain. These cells fire spontaneously at a relatively low rate, typically $2-8 \mathrm{~Hz}$ (Pennartz et al., 2002; Jackson et al., 2004; Belle et al., 2009) which is well mimicked by a recently published ionic model (Sim and Forger, 2007) as shown in the inset of Figure 7. A key component of the model is the description of $I_{\mathrm{K}}$ by Bouskila and Dudek (1995). They obtained the $I_{\mathrm{K}}$ activation curve using normalization by $\left(V-E_{\mathrm{K}}\right)$ - open circles in Figure 7. Normalization by GHK $\left[\left(V-E_{\mathrm{K}}\right)\right]$ gives the filled circles in Figure 7. The activation curve is made steeper and shifted leftward on the voltage axis, as with $I_{\mathrm{A}}$ from CajalRetzius cells and $I_{\mathrm{K}}$ in squid axons (Figures 3 and 5, respectively). This modification in the SCN model removes spontaneous firing thereby yielding a quiescent preparation having a rest potential of $-36 \mathrm{mV}$ (Figure 7 inset). The revised model fails to produce an action potential even in response to strong depolarizations (results not shown). The mechanism for this result concerns the relative position and steepness of the "foot" of the $I_{\mathrm{K}}$ activation curve (Figure 7). Removal of $I_{\mathrm{Na}}$ (addition of TTX) in the original SCN model (Sim and Forger, 2007) produces quiescence with a rest potential at $-62 \mathrm{mV}$. The revised model rests at $-36 \mathrm{mV}$ even with retention of $I_{\mathrm{Na}}$. The foot of the $I_{\mathrm{K}}$ curve in the original model has a larger value at $-40 \mathrm{mV}$ compared to the revised version. Even at $-60 \mathrm{mV}$ this curve is significantly greater than 0 (Figure 7). The foot of the curve in the revised version has a smaller value than the original at $-40 \mathrm{mV}$ and is essentially 0 at $-60 \mathrm{mV}$. The revised model allows the "leak" current to depolarize the membrane potential to a level where $I_{\mathrm{Na}}$ is almost completely 


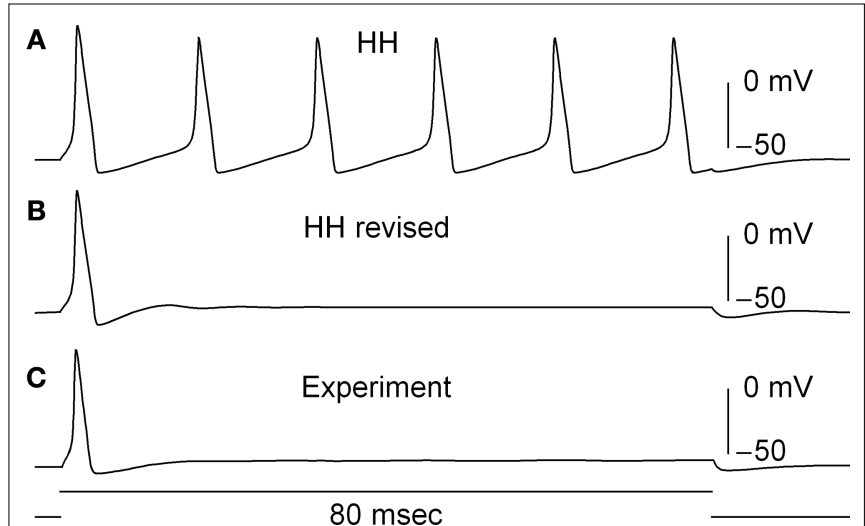

FIGURE 6 | Effect of GHK normalization of $I_{\mathrm{K}}$ in a model of squid axon excitability. (A) Prediction of the response of the Hodgkin and Huxley (1952) model to a sustained depolarizing current pulse. The model fires an unending train of action potentials. (B) Prediction of the revised model (Clay et al., 2008) with the modified $l_{\mathrm{K}}$ activation curve given in Figure 5. The revised model fires once and only once regardless of pulse duration or amplitude, similar to experimental observations, as illustrated in (C).

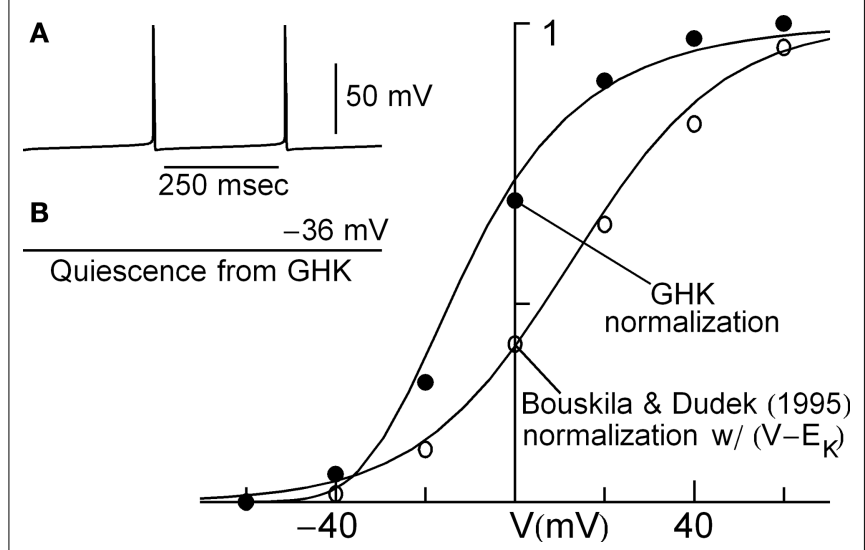

FIGURE 7 | Effect of GHK normalization of $I_{\mathrm{K}}$ in a model of electrical activity of neurons from the suprachiasmatic nucleus by $\mathrm{Sim}$ and Forger (2007). Inset (A) Prediction of the Sim and Forger (2007) model. (B) Prediction of the model when GHK normalization is used to obtain the $g_{\mathrm{K}}-V$ curve from the Bouskila and Dudek (1995) measurements of $I_{K}$ described to the right. Main panel: description of $I_{K}$ by Bouskila and Dudek (1995). They normalized their results with $\left(V-E_{k}\right)$ - open circles. The curve describing those results is given by $1 /(1+\exp (-(v-14) / 17))$. Those points were multiplied by $\left(V-E_{K}\right)$ with $E_{\mathrm{K}}=-97 \mathrm{mV}$, and then normalized by the GHK procedure to give the filled circles. The curve describing those results is given by $\left(\alpha_{n} /\left(\alpha_{n}+\beta_{n}\right)^{4}\right.$ with $\alpha_{n}=-0.01(V+30) /(\exp (-0.08(V+30))-1)$ and $\beta_{n}=0.125 \exp (-(V+40) / 30)$. This description of $I_{K}$ predicts quiescence in the Sim and Forger (2007) model as described in the text.

inactivated at rest. The original $I_{\mathrm{K}}$ curve repolarizes the membrane potential to a level following an action potential at which $I_{\mathrm{Na}}$ inactivation is incomplete. Consequently, repetitive spontaneous firing of action potentials occurs in the original but not in the revised model.

The squid and the SCN results can be summarized by saying that normalization of $I_{\mathrm{K}}$ by GHK reduces excitability in models for both preparations. The GHK modification produces agreement between experiment and theory for squid axons but not for SCN neurons. Further modifications in the SCN model will be necessary to bring the model in agreement with experimental results.

\section{A CAUTIONARY NOTE CONCERNING GHK NORMALIZATION}

External factors can sometimes mask the GHK voltage dependence of the current-voltage relation. An example is provided by the $\mathrm{Na}^{+}$current in squid axons (Vandenberg and Bezanilla, 1991). The current-voltage relation of this channel is fundamentally described by GHK[ $\left.\left(V-E_{\mathrm{Na}}\right)\right]$ as illustrated in Figure 8 (open circles). The curvature of this relation is in the opposite direction to that of $\mathrm{GHK}\left[\left(V-E_{\mathrm{K}}\right)\right]$ because the external $\mathrm{Na}^{+}$concentration is significantly higher than $\mathrm{Na}_{\mathrm{i}}^{+} \cdot \mathrm{Na}^{+}$channels are blocked in a voltagedependent manner by extracellular divalent cations (Yamamoto et al., 1984) which are present in significant amounts in seawater $\left(\mathrm{Ca}^{2+}=10 \mathrm{mM}\right.$ and $\left.\mathrm{Mg}^{2+}=50 \mathrm{mM}\right)$, giving a current-voltage relation for physiological conditions which is nearly linear over the voltage range spanned by an action potential $(-70$ to +40 ; filled circles in Figure 8). Normalization of peak $I_{\mathrm{Na}}$ results by $\mathrm{GHK}\left[\left(V-E_{\mathrm{Na}}\right)\right]$ would give an incorrect description of the $\mathrm{Na}^{+}$channel activation curve in squid. Normalization of those results by $\left(V-E_{\mathrm{Na}}\right)$ as originally carried out by Hodgkin and Huxley (1952) is serendipitously correct because of divalent cation block of $I_{\mathrm{Na}}$. A similar result may occur for other types of channels. For example, delayed rectifier $\mathrm{K}^{+}$channels (but apparently not $I_{\mathrm{A}} \mathrm{K}^{+}$channels) are partially blocked by physiological levels of $\mathrm{Na}_{\mathrm{i}}^{+}$for $V>0 \mathrm{mV}$ (Bezanilla and Armstrong, 1972) which can confound the activation curve analysis for high-voltage-activated channels such as Kv3.1 and Kv3.2 (Hernandenz-Pineda et al., 1999). In particular, $\mathrm{Na}_{\mathrm{i}}$ block of $I_{\mathrm{K}}$ can give an apparent saturation of channel activation using normalization by $\left(V-E_{K}\right)$, a result which would not be found in the absence of $\mathrm{Na}_{\mathrm{i}}^{+}$. At some point in the experimental description of an ionic current in any preparation a measurement of the current-voltage relation of the channel is required to determine the appropriateness of GHK for those results.

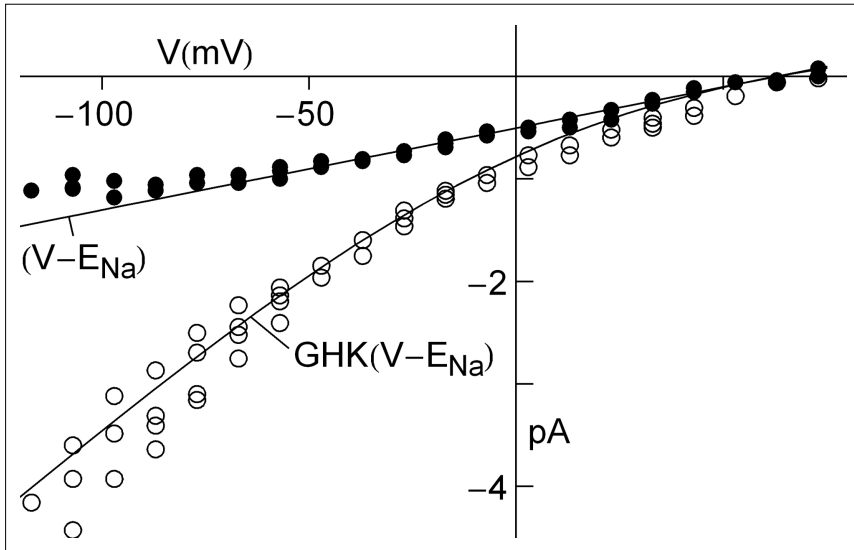

FIGURE 8 | GHK analysis of $\mathrm{Na}^{+}$current in squid giant axons (Vandenberg and Bezanilla, 1991). The open circles were obtained using divalent-free artificial seawater. The filled circles were obtained under normal divalent cation conditions, $\mathrm{Ca}^{2+}=10 \mathrm{mM}$ and $\mathrm{Mg}^{2+}=50 \mathrm{mM}$. The latter results are well described by $\left(V-E_{10}\right)$ over the range of potentials spanned by an action potential $(-70$ to $+40 \mathrm{mV})$ because of partial, voltage-dependent block of $I_{\mathrm{Na}}$ by $\mathrm{Ca}^{2+}$ and $\mathrm{Mg}^{2+}$ 


\section{SUMMARY}

The results reviewed here are surprising for some investigators. The relation $I=g(V-E)$ with $E \neq 0$ as is the case for most ions under physiological conditions has dogmatic status in neuroscience. The simplicity of this equation may be one of the reasons it has been largely unchallenged. Experimental observations have shown that the current-voltage relation for ion channels rectifies in a manner determined by the respective extra- and intracellular concentrations of the ion in question. The strongest evidence for this result for $\mathrm{K}^{+}$channels are the single channel recordings in Apysia sensory neurons by Siegelbaum et al. (1982) in physiological conditions $\left(\mathrm{K}_{\mathrm{i}}^{+}=360 \mathrm{mM} ; \mathrm{K}_{\mathrm{o}}^{+}=10 \mathrm{mM}-\right.$ the $\mathrm{K}^{+}$concentration of seawater $)$. The voltage dependence of those results is well described by the GHK equation. Given the similarity of $\mathrm{K}^{+}$currents for most if not all cell types, similar results would be expected for single channel recordings from other preparations.

The non-linearity of the GHK equation is removed for equimolar conditions, i.e., $\mathrm{K}_{\mathrm{i}}^{+}=\mathrm{K}_{\mathrm{o}}^{+}$. In many preparations the extracellular medium can be exchanged for one in which this condition is obtained, i.e., an increase in $\mathrm{K}_{\mathrm{o}}^{+}$to closely match $\mathrm{K}_{\mathrm{i}}^{+}$. Depolarizing voltage steps from a relatively negative holding potential as was used for the $I_{\mathrm{A}}$ results in Figures 3 and 4 would elicit inward $\mathrm{K}^{+}$currents for these conditions for $V<0 \mathrm{mV}$. The activation curve from those results could be obtained using linear voltage normalization without introducing the error described in this report when normalizing $\mathrm{K}^{+}$ currents in physiological conditions by $\left(V-E_{\mathrm{K}}\right)$. Alternatively, as noted above, tail currents could be used for this analysis without increasing $\mathrm{K}_{\mathrm{o}}^{+}$. Tail currents are usually measured at a fixed potential (the holding potential) which would eliminate the GHK nonlinearity in the analysis of the $g_{\mathrm{K}}-V$ curve. However, this approach is not feasible for some types of $\mathrm{K}^{+}$channels, in particular $I_{\mathrm{A}}$. Tail currents from $I_{\mathrm{A}}$ are typically too small to be reliably measured given the strong inactivation of this component which occurs with membrane depolarization. Consequently, normalization of a family of currents by $\mathrm{GHK}\left[\left(V-E_{\mathrm{K}}\right)\right]$ is particularly relevant for $I_{\mathrm{A}}$.

The terms permeability and conductance have been widely used throughout the neuroscience literature. Permeability, $P$, has units of $\mathrm{cm} / \mathrm{sec}$. A comparison of Eqs 1 and 2 demonstrates that at the single channel level $P_{\mathrm{K}} \sim a q N_{\mathrm{K}} F^{-1}$ which also has units of $\mathrm{cm} / \mathrm{sec}$ with $a$ being a factor describing collisions of $\mathrm{K}$ ions with the membrane, $q$ is the elementary electronic charge, $N_{\mathrm{K}}$ is the $\mathrm{K}^{+}$channel density, and $F$ is the Faraday. A single value of $P$ is sufficient and appropriate for the current-voltage (I-V) relation of $\mathrm{K}^{+}$channels for physiological conditions. The non-linearity of the $\mathrm{I}-\mathrm{V}$ result is given by the other terms either in Eq. 1 or 2. A single value of conductance, $G$, cannot be used for the I-V curve for physiological conditions. The slope conductance can be used, but that number changes with voltage. For example, the delayed rectifier channel in squid axons is

\section{REFERENCES}

Belle, M. D. C., Diekman, C. O., Forger, D. B., and Piggins, H. D. (2009). Daily electrical silencing of the mammalian circadian clock. Science 326, 281-284.

Berneche, S., and Roux, B. (2001). Energetics of ion conduction through the $\mathrm{K}^{+}$channel. Nature 414, 73-77.
Bezanilla, F., and Armstrong, C. M. (1972). Negative conductance caused by the entry of sodium and cesium ions into the potassium channels of squid axons. J. Gen. Physiol. 60, 588-608.

Binstock, L., and Goldman, L. (1971). Rectification in instantaneous potassium current voltage relations in typically described as having a single channel conductance of $20 \mathrm{pS}$ for physiological conditions (Llano et al., 1988). Those results were obtained for $V=+50 \mathrm{mV}$. According to the GHK voltage dependence (Eq. 3), the single channel (slope) conductance at $V=-50 \mathrm{mV}$ would be $2 \mathrm{pS}$. A single value of $G$ can be used for equimolar conditions, i.e., $\mathrm{K}^{+}=\mathrm{K}_{\mathrm{o}}^{+}=\mathrm{K}_{\mathrm{i}}^{+}$. For those conditions $I_{\mathrm{K}}=P_{\mathrm{K}} F(F V / R T) K^{+}=G_{\mathrm{K}} V$, or $G_{\mathrm{K}}=P_{\mathrm{K}} F^{2} K^{+} /(R T)$. At the single channel level, $G_{\mathrm{K}}=\gamma_{\mathrm{K}} N_{\mathrm{K}}$, where $\gamma_{\mathrm{K}}$ is the single channel conductance. From the above discussion concerning permeability, this expression is comparable to aq $\mathrm{N}_{\mathrm{K}} \mathrm{FK}^{+}$/ $(R T)$, so that $\gamma_{\mathrm{K}} \approx a q \mathrm{~K}^{+} /(25 \mathrm{mV})$, given that $R T / F=25 \mathrm{mV}$ at room temperature. This expression is only an approximation primarily to give a sense of the units of the various terms involved. The detailed mechanism of ion translocation through $\mathrm{K}^{+}$selective channels at the molecular level of channel proteins is a topic of on-going research (Berneche and Roux, 2001; Fowler et al., 2008; and many other reports referenced in these studies).

One final point concerning the utility of the GHK equation for models of membrane excitability is that it permits a straightforward determination of $I_{\mathrm{K}}$ when $\mathrm{K}_{\mathrm{o}}^{+}=0$, conditions which are problematic for $I_{\mathrm{K}} \sim\left(V-E_{\mathrm{K}}\right)$ since $E_{\mathrm{K}}$ is undefined for $\mathrm{K}_{\mathrm{o}}^{+}=0$ (Clay, 1998). [Note that $\mathrm{K}_{\mathrm{o}}^{+}\left(\exp \left(\left(V-E_{\mathrm{K}}\right) / 25\right)-1\right)=\mathrm{K}_{\mathrm{i}}^{+} \exp (\mathrm{V} / 25)$ when $\mathrm{K}_{\mathrm{o}}^{+}=0$. The observation that $P_{\mathrm{K}}$ in squid axons is 10 times higher than in frog nerve may be of historical interest. The action potential of squid giant axons has a robust after-hyperpolarization potential (AHP) (Hodgkin and Huxley, 1952), whereas frog nerve does not (Frankenhauser and Huxley, 1964). The difference in $P_{\mathrm{K}}$ 's provides an explanation for these results.

The primary thrust of this review concerns the use of GHK normalization to obtain ion channel activation curves for the delayed rectifier $I_{\mathrm{K}}$ and for $I_{\mathrm{A}}$. A number of groups (DeFazio and Moenter, 2002; Boland et al., 2003; Van Hoorick et al., 2003; Persson et al., 2005; Nakamura and Takahashi, 2007; Johnston et al., 2008; Dementieva et al., 2009; Sculptoreanu et al., 2009) have recently used the procedure outlined here and in a previous report from this laboratory (Clay, 2000) to obtain these results. One of the purposes of this review is to encourage others to do the same. An accurate description of $\mathrm{K}^{+}$channel activation curves is important for models of neuronal excitability as illustrated by the above examples - squid giant axons and SCN neurons - and for models of $\mathrm{K}^{+}$channel gating. Model building for the excitability properties of neurons in the mammalian brain is an evolving discipline. The analysis given here is one issue which should be kept in mind when constructing models of this type.

\section{ACKNOWLEDGEMENT}

This work was supported by the Intramural Research Program of the National Institute of Neurological Disorders and Stroke, National Institutes of Health, Bethesda, MD, USA.
Myxicola giant axons. J. Physiol. (Lond.) 217, 517-531.

Boland, L. M., Jiang, M., Lee, S. Y., Fahrenkrug, S. C., Haranett, M. T. G., and Ogrady, S. M. (2003). Functional properties of a brain-specific NH2terminally spliced modulator of KV4 channels. Am. J. Physiol. Cell. Physiol. 285, C161-C170.
Bouskila, Y., and Dudek, F. E. (1995). A rapidly activating type of outward rectifier $\mathrm{K}^{+}$current and $\mathrm{A}$-current in rat suprachiasmatic nucleus neurons. J. Physiol. (Lond.) 488, 339-350.

Campbell, D. L., Rasmussen, R. L., Qu, Y., and Strauss, H. C. (1993). The calcium-independent transient outward potassium current in isolated 
ferret right ventricalmyocytes. I. Basic characterization and kinetic analysis. J. Gen. Physiol. 101, 571-601.

Clay, J. R. (1991). A paradox concerning ion permeation of the delayed rectifier potassium ion channel in squid giant axons. J. Physiol. (Lond.) 444, 499-511.

Clay, J. R. (1998). Excitability of the squid giant axon revisited. J. Neurophysiol. 80, 903-913.

Clay, J. R. (2000). Determining $\mathrm{K}^{+}$channel activation curves from $\mathrm{K}^{+}$channel currents. Eur. J. Biophys. 29, 555-557.

Clay, J. R., Paydarfar, D., and Forger, D. B. (2008). A simple modification of the Hodgkin and Huxley equations explains type 3 excitability in squid giant axons. J. R. Soc. Interface 5 , 1421-1428.

Connor, J. A., and Stevens, C. F. (1971). Prediction of repetitive firing behavior from voltage clamp data on an isolated neuron soma. J. Physiol. (Lond.) 213, 31-53.

Conti, F., DeFelice, L. J., and Wanke, E. (1975). Potassium and sodium ion current noise in the membrane of the squid giant axon. J. Physiol. (Lond.) 248, 45-82.

DeFazio, R.A., and Moenter, S.M. (2002). Estradiol feedback alters potassium currents and firing properties of gonadotropin-releasing hormone neurons. Mol. Endocrinol. 16, 2255-2265.

Dementieva, I.S., Tereshko, V., McCrossen, Z. A., Solomaha, E., Araki, D., Xu, D., Grigorieff, N., and Goldstein, S. A. N. (2009). Pentameric assembly of potassium channel tetramerization domain-containing protein 5. J. Mol. Biol. 387, 175-191.

Fowler, P.W., Tai, K., and Sansom, M. S. P. (2008). The selectivity of $\mathrm{K}^{+}$ion channels: testing the hypotheses. Biophys. J. 95, 5062-5072.

Frankenhauser, B. (1962). Potassium permeability in myelinated nerve fibers of Xenopus laevis. J. Physiol. (Lond.) 160, 54-61.

Frankenhauser, B., and Huxley, A. F. (1964). The action potential in the myelinated nerve fiber of Xenopus laevis as computed on the basis of voltage clamp data. J. Physiol. (Lond). $171,302-315$.
Goldman, D. E. (1943). Potential, impedance, and rectification in membranes. J. Gen. Physiol. 27, 37-60.

Hernandenz-Pineda, R.,Chow,A.,Amarillo, Y., Moreno, H., Saganech, M., de Miera, V.-S.,Hernandez-Cruz, A., and Rudy, B. (1999). Kv3.1-Kv3.2 channels underlie a high voltage-activating component of the delayed rectifier $\mathrm{K}^{+}$current in projecting neurons from the globus pallidus. J. Neurophysiol. 82, 1512-1528.

Hille,B. (2001).Ionic Channels of Excitable Membranes, 3rd edn. Sunderland, Sinaur Press, pp. 400-402.

Hodgkin, A. L., and Huxley, A. F. (1952). A quantitative description of membrane current and its application to conductance and excitation in nerve. J. Physiol. (Lond.) 117, 500-544.

Hodgkin, A. F., and Katz, B. (1949). The effect of sodium ions on the electrical activity of a giant nerve fiber. J. Physiol. (Lond.) 108, 37-77.

Hodgkin, A. F., and Keynes, R. D. (1955). The potassium permeability of a giant nerve fiber. J. Physiol. (Lond.) 128, 61-88.

Jackson, A. C., Yao, G. L., and Bean, B. P. (2004). Mechanism of spontaneous firing indorsomedial suprachiasmatic nucleus neurons. J. Neurosci. 24, 7985-7998.

Jan, L. Y., and Jan, Y. N. (1997). Cloned potassium channels from eukaryotes and prokaryotes. Ann. Rev. Neurosci. 29, 91-123.

Johnston, J., Griffin, S. J., Baker, C., and Forsythe, I. D. (2008). Kv4 (A-type) potassium currents in the mouse medial nucleus of the trapezoid body. Eur. J. Neurosci. 27, 1391-1399.

Khaliq, Z. M., and Bean, B. P. (2008). Dynamic, nonlinear feedback regulation of slow pacemaking by A-type potassium current in ventral tegmental area neurons. J. Neurosci.28, 10905-10917.

Kohler, H.-H., and Heckmann, K. (1979). Unidirectional fluxes in saturated single file pores of biological and artificial membranes. I. Pores containing no more than one vacancy. J. Theor. Biol. 79, 381-401.

Llano, I., Webb, C. K., and Bezanilla, F. (1988). Potassium conductance of the squid giant axon. Single-channel studies. J. Gen. Physiol. 92, 179-196.

Mienville, J.-M., and Barker, J. L. (1997). Potassium current expression during prenatal cortocogenesis in the rat. Neuroscience 81, 163-172.

Mienville, J.-M., Maric, I., Maric, D., and Clay, J. R. (1999). Loss of IA expression and increased excitability in postnatal rat Cajal-Retzius cells. J. Neurophysiol. 82, 1303-1310.

Nakamura, Y., and Takahashi, T. (2007) Developmental changes in potassium currents at the rat calyx of held presynaptic terminal.J. Physiol. (Lond.) 581, 1101-1112.

Pennartz, C. M. A., de Jeu, M. T. G., Bos, N.P.A., and Geurtsen, A. M. S. (2002), Diurnal modulation of pacemaker potentials and calcium current in the mammalian circadian clock. Nature 416, 286-290.

Persson, F., Carlsson, L., Duker, G., and Jakobson, I. (2005). Blocking characteristics of hKv1.5 and hKc4.3/ hKCHIP2.2 after administration of the novel antiarrhythimic compound AZD7009. J. Cardiovasc. Pharmacol. 46, 7-17.

Rush, M. E., and Rinzel, J. (1995). The potassium A-current, low firing rates and rebound excitation in HodgkinHuxley models. Bull. Math. Biol. 57, 899-929.

Sculptoreanu, A., Artim, D. E., and deGroat, W. (2009). Neurokinins inhibit low threshold inactivating $\mathrm{K}^{+}$ currents in capsaicin responsive DRG neurons. Expt. Neurol. 219, 562-573.

Shumaker, M. F., and MacKinnon, R. (1990). A simple model for multi-ion permeation. Single-vacancy conduction in a simple pore model. Biophys. J. 58, 975-984.

Siegelbaum, S. A., Camardo, J. S., and Kandel, E. R. (1982). Serotonin and cAMP close single $\mathrm{K}$ channels in Aplysia sensory neurons. Nature 299, 413-417.

Sigworth, F. (2003). Structural biology: life's transistors. Nature 423, 21.

Sim, C. K., and Forger, D. B. (2007). Modeling the electrophysiology of suprachiasmatic nucleus neurons. $J$. Biol. Rhythms 22, 445-453.
Taglialatela, M., and Stefani, E. (1993). Gating currents of the cloned delayed rectifier $\mathrm{K}^{+}$channel DRK1. Proc. Natl. Acad. Sci. U.S.A. 90, 4758-4762.

Van Hoorick, D., Raes, A., Keysers, W., Mayeur, E., and Snyders, D. J. (2003). Differential modulation of KV3 kinetics by KCHIP1 splice variants. Mol. Cell. Neurosci. 24, 357-366.

Vandenberg, C.A., and Bezanilla, F. (1991) Single-channel, macroscopic, and gating currents from sodium channels in the squid giant axon. Biophys. J. 60, 1499-1510.

Yamamoto, D., Yeh, J. Z., and Narahashi, T. (1984). Voltage-dependent calcium block of normal and tetromethrinmodified single sodium channels. Biophys. J. 45, 337-344.

Zagotta, W. N., Hoshi, T., and Aldrich, R. W. (1994). Shaker potassium channel gating. III. Evaluation of kinetic models for activation. J. Gen. Physiol. 103, 321-362.

Zhou, Y., Morais-Cabral, J. H., Kaufman, A., and MacKinnon, R. (2001) Chemistry of ion coordination and hydration revealed by a $\mathrm{K}^{+}$channel-Fab complex at $2.0 \AA$ resolution. Nature 414, 43-48.

Conflict of Interest Statement: This research was conducted in the absence of any commercial or financial relationships that could be construed as a potential conflict of interest.

Received: 16 October 2009; paper pending published: 23 November 2009; accepted: 07 December 2009; published online: 23 December 2009

Citation: Clay JR (2009) Determining $\mathrm{K}^{+}$channel activation curves from $\mathrm{K}^{+}$channel currents often requires the Goldman-Hodgkin-Katz equation. Front. Cell. Neurosci. 3:20. doi 10.3389/neuro.03.020.2009

Copyright () 2009 Clay. This is an open-access article subject to an exclusive license agreement between the authors and the Frontiers Research Foundation, which permits unrestricted use, distribution, and reproduction in any medium, provided the original authors and source are credited. 